\title{
COMPARAÇÃO DE PARÂMETROS DE CRESCIMENTO E DE DESENVOLVIMENTO DE DOIS BIÓTIPOS DE ARROZ VERMELHO COM GENÓTIPOS DE ARROZ IRRIGADO (1)
}

\author{
NEREU AUGUSTO STRECK $\left({ }^{2 *}\right)$; SIMONE MICHELON $\left({ }^{3}\right)$; NELSON DIEHL KRUSE $\left({ }^{4}\right)$; \\ LEOSANE CRISTINA BOSCO $\left({ }^{3}\right)$; ISABEL LAGO $\left({ }^{3}\right)$; ELIO MARCOLIN $\left({ }^{5}\right)$; GIZELLI MOIANO DE PAULA $\left({ }^{6}\right)$; \\ FLÁVIA KAUFMANN SAMBORANHA $\left({ }^{6}\right)$
}

\begin{abstract}
RESUMO
Caracterizar o crescimento e desenvolvimento de biótipos de arroz vermelho pode ajudar no seu controle e no melhoramento para aumentar a competitividade do arroz cultivado com esta planta daninha. O objetivo deste trabalho foi quantificar parâmetros de crescimento e desenvolvimento de dois biótipos de arroz vermelho e compará-los com genótipos de arroz irrigado. Desenvolveu-se um experimento de campo em Santa Maria (RS), durante o ano agrícola 2004/2005 com cinco épocas de semeadura. O delineamento experimental utilizado foi o inteiramente casualizado com quatro repetições no esquema bifatorial (genótipos e épocas de semeadura). A unidade experimental foi um balde de 12 litros com dez plantas. Os genótipos utilizados foram: IRGA 421, IRGA 416, IRGA 417, IRGA 420, BR-IRGA 409, BRS 7 TAIM e EPAGRI 109 (tipo moderno), EEA 406 (tipo tradicional), um híbrido, arroz vermelho casca amarela com arista (AVCAA) e arroz vermelho casca preta com arista (AVCPA). A data dos principais estágios de desenvolvimento da escala de COUNCE, área foliar, comprimento de panícula, estatura de planta, filocrono, número final de folhas no colmo principal e perfilhamento foram avaliados em cinco plantas por balde. Nos biótipos de arroz vermelho geralmente observa-se ciclo de desenvolvimento médio em relação aos genótipos cultivados, sendo o biótipo AVCAA de ciclo mais longo que o biótipo AVCPA. Os biótipos de arroz vermelho tiveram área foliar, estatura, panícula e filocrono maiores que os genótipos modernos de arroz. O perfilhamento dos biótipos de arroz vermelho foi variável e dependente da época de semeadura.
\end{abstract}

Palavras-chave: características morfológicas, filocrono, fenologia, planta daninha.

( $\left.{ }^{1}\right)$ Recebido para publicação em 23 de agosto de 2006 e aceito em 23 de novembro de 2007.

$\left({ }^{2}\right)$ Departamento de Fitotecnia, Centro de Ciências Rurais (CCR), Universidade Federal de Santa Maria (UFSM), Avenida Roraima, 1000, 97105-900, Santa Maria (RS), Brasil. E-mail: nstreck1@smail.ufsm.br $\left({ }^{*}\right)$ Autor correspondente. Bolsista de Produtividade em Pesquisa do Conselho Nacional de Desenvolvimento Científico e Tecnológico (CNPq).

$\left({ }^{3}\right)$ Programa de Pós-Graduação em Agronomia, UFSM, Santa Maria (RS), Brasil. Bolsista de Mestrado da Coordenação de Aperfeiçoamento de Pessoal de Nível superior (CAPES).

$\left({ }^{4}\right)$ Departamento de Defesa Fitossanitária, CCR, UFSM.

$\left({ }^{5}\right)$ Instituto Rio Grandense do Arroz (IRGA), Rua Bonifácio Carvalho Bernardo, 1494, Caixa Postal 29, 94930-030 Cachoeirinha (RS).

$\left({ }^{6}\right)$ Curso de Agronomia, CCR, UFSM. 


\title{
ABSTRACT GROWTH AND DEVELOPMENTAL OF RED AND PAD RICE GENOTYPES
}

\begin{abstract}
The characterization growth and development of red rice biotypes may help controll strategies, the enhancement of competitiveness of cultivated rice with this weed and breeding programs. The objective of this is study was to quantity some growth and development parameters of two red rice biotypes as compared to irrigated genotypes. A field experiment was carried out at Santa Maria, Rio Grande do Sul State, Brazil, during the 2004/2005 growing season with five sowing dates. The experimental design was a completely randomized with four replication in a two factorial arrangement (genotypes and sowing dates). The experimental unity was a $12 \mathrm{~L}$ pot with 10 plants. The genotypes used were: IRGA 421, IRGA 416, IRGA 417, IRGA 420, BR-IRGA 409, BRS 7 TAIM, EPAGRI 109, EEA 406, a hybrid, and two red rice biotypes (awned yellowhull-AVCAA, and awned blackhull-AVCPA). The date of major developmental stages in the COUNCE scale, leaf area, panicle length, plant height, phyllochron, main culm final leaf number, and tillering were measured in five plants per pot. Red rice biotypes usually had an intermediate developmental cycle compared to cultivated rice genotypes, with AVCAA having a longer cycle than AVCPA. Red rice biotypes had greater leaf area, greater height, greater panicle length and greater phyllochron, than modern rice genotypes. Tillering of red rice varied according to the sowing date.
\end{abstract}

Key words: morphological characteristics, phyllochron, phenology, weed.

\section{INTRODUÇÃO}

O arroz integra a dieta básica de, aproximadamente, $50 \%$ da população mundial (FAGERIA et al., 2003). No Brasil, existem cerca de 35 milhões de hectares de várzeas sendo 1,3 milhões utilizados na produção de arroz irrigado (FAGERIA et al., 2003). A produção brasileira de arroz representa em torno de $1,8 \%$ da produção mundial e $52 \%$ da produção da América do Sul. A Região Sul do Brasil (Rio Grande do Sul, Santa Catarina e Paraná) é a principal produtora, com $63 \%$ do total produzido no País. O Rio Grande do Sul é o maior produtor nacional representando $77 \%$ do arroz irrigado colhido no país (Azambuja et al., 2004). No Rio Grande do Sul, na safra de 2004/2005, a área cultivada foi de 1.031.000 ha e produtividade de $6,68 \mathrm{t} \mathrm{ha}^{-1}$ (IRGA, 2006). No entanto, o rendimento de grãos no Estado está abaixo do potencial da cultura obtido em áreas experimentais que, para as cultivares IRGA 410, IRGA 417 e IRGA 420 atingem 11 a $12 \mathrm{t} \mathrm{ha}^{-1}$ (MARIOT et al., 2003; LOPES et al., 2005a,b,c,d).

Dentre os fatores que contribuem para o rendimento de arroz irrigado a campo ser menor que o rendimento potencial no Rio Grande do Sul, destacase a presença de arroz vermelho (Oryza sativa L.), considerada a principal planta daninha de lavouras orizícolas (MARCHEZAN, 1994; MARCHEZAN et al., 2004). $\mathrm{O}$ arroz vermelho pertence à mesma espécie do arroz cultivado (Oryza sativa L.), o que dificulta seu controle. Sua presença em áreas cultivadas resulta em competição intra-específica com o arroz cultivado pelos recursos do meio, causa acamamento, além de aumentar o custo de produção devido à necessidade de maior número de aplicações de herbicidas (Menezes et al., 2002). Mesmo após a colheita, a presença do arroz vermelho é prejudicial, pois interfere no processo de beneficiamento, aumentando o período de secagem e polimento dos grãos, devido à cor avermelhada do pericarpo podendo aumentar a porcentagem de grãos quebrados (MARCHEZAN, 1993; 1994; Menezes et al., 1997).

Caracterizar o crescimento e desenvolvimento de biótipos de arroz vermelho pode ser de grande valia para estabelecer estratégias de controle desta planta daninha e auxiliar no melhoramento do arroz cultivado, a fim de aumentar sua competitividade frente à planta daninha (KwoN et al., 1992). Alguns parâmetros de crescimento do arroz vermelho, citados como diferentes do arroz cultivado, no entanto, nem sempre são observados em resultados de pesquisa, a exemplo do número de perfilhos planta ${ }^{-1}$. Menezes et al. (2002) não verificaram diferenças para número de perfilhos planta ${ }^{-1}$ entre diferentes biótipos de arroz vermelho e as cultivares BR-IRGA 410 e IRGA 416. KwON et al. (1992) observaram maior número de colmos planta $^{-1}$ aos 20 dias após a emergência (DAE) e não verificaram diferenças para número de colmos planta ${ }^{-}$ 1 aos 80 DAE entre o arroz vermelho e o arroz cultivado. Já Noldin et al. (1999) constararam 46\% mais perfilhos em plantas de biótipos de arroz vermelho do que em cultivares de arroz cultivado. Essas discrepâncias entre diferentes trabalhos podem ocorrer pelas variações genéticas dos biótipos de arroz vermelho ou pelas diferenças entre os protocolos experimentais utilizados.

Alguns parâmetros de desenvolvimento, como o filocrono, definido como o tempo, em ${ }^{\circ} \mathrm{C}$ dia, necessário para o aparecimento de uma folha no colmo (Rickman e Klepper, 1995; SkinNer e Nelson, 1995; WilHeLm e McMaster, 1995), o número final de folhas 
no colmo principal e a duração do ciclo, em ${ }^{\circ} \mathrm{C}$ dia, para biótipos de arroz vermelho, não foram constatados na literatura. Esses três parâmetros podem ser de interesse na área de plantas daninhas, pois o filocrono é um parâmetro útil para caracterizar o desenvolvimento na fase vegetativa (emissão de folhas), o número final de folhas no colmo principal tem relação direta com o ciclo total de desenvolvimento (STRECK et al., 2006) e os ${ }^{\circ} \mathrm{C}$ dia do ciclo total caracterizam as necessidades térmicas do arroz vermelho.

Variações morfológicas entre biótipos de arroz vermelho são esperadas em função da possibilidade de cruzamento com o arroz cultivado (GeAly et al., 2003). Esse fato pode gerar diferentes biótipos de arroz vermelho em regiões agroecológicas distintas e criar a oportunidade de constante modificação e adaptação desses biótipos nas lavouras orizícolas. Essa possibilidade e o fato de que alguns parâmetros de desenvolvimento ainda não foram quantificados para o arroz vermelho constituíram o incentivo para este esforço científico. O objetivo deste trabalho foi comparar parâmetros de crescimento e de desenvolvimento de dois biótipos de arroz vermelho e compará-los com genótipos de arroz irrigado.

\section{MATERIAL E MÉTODOS}

Um experimento foi desenvolvido em campo com semeadura em baldes durante o ano agrícola 2004/2005 na área experimental do Departamento de Fitotecnia da Universidade Federal de Santa Maria, Santa Maria (RS), Brasil (latitude: $29^{\circ} 43^{\prime}$ S, longitude: $53^{\circ} 43^{\prime} \mathrm{W}$ e altitude: $95 \mathrm{~m}$ ). O clima da região, segundo a classificação de Köppen, é Cfa que significa subtropical úmido sem estação seca definida, com verões quentes (Moreno, 1961). O solo do local é uma transição entre a Unidade de Mapeamento São Pedro (Argissolo Vermelho distrófico arênico) e a Unidade de Mapeamento Santa Maria (Alissolo Hipocrômico argilúvico típico) (EMBRAPA, 1999).

As plantas de arroz foram cultivadas em baldes de $30 \mathrm{~cm}$ de diâmetro e $26 \mathrm{~cm}$ de altura com capacidade de 12 litros, preenchidos com solo do local e enterrados, deixando-se uma borda de $5 \mathrm{~cm}$ acima do nível do solo. $\mathrm{O}$ espaçamento entre os baldes (de centro a centro) foi de 1,5 $\mathrm{m} \times 0,8 \mathrm{~m}$. Foram realizadas cinco semeaduras nas seguintes datas: $2 / 9 / 2004,7 /$ $10 / 2004,4 / 11 / 2004,3 / 12 / 2004$ e $2 / 3 / 2005$. Essas datas foram usadas por se situarem antes, durante e após a época recomendada de semeadura para a região que é de $10^{\circ} / 10$ a 10/12 (Sosbai, 2005). Dessa forma, obtiveram-se plantas com crescimento e desenvolvimento em condições meteorológicas distintas. O delineamento experimental utilizado foi o inteiramente casualizado com quatro repetições no esquema fatorial (genótipos e datas de semeadura). Cada unidade experimental foi representada por um balde com 10 plantas.

As cultivares utilizadas foram IRGA 421 (muito precoce), IRGA 416 (precoce), IRGA 417 (precoce), IRGA 420 (médio), BRS 7 TAIM (médio), BRIRGA 409 (médio), EPAGRI 109 (tardio) (SosbaI, 2005), EEA 406, um genótipo híbrido do Instituto Rio Grandense do Arroz (IRGA) ainda não liberado comercialmente e, por isso, denominado aqui apenas como híbrido, e dois biótipos de arroz vermelho, um biótipo com grãos casca preta e aristado (AVCPA) e o outro biótipo com casca amarela e aristado (AVCAA). As sementes dos dois biótipos originaramse de uma única planta para cada biótipo, cultivadas na área experimental do Instituto Riograndense do Arroz (IRGA), em Cachoeirinha, RS, no ano agrícola 2003/2004. As cultivares são todas da subespécie indica, tipo moderno, exceto EEA 406, que é da subespécie japônica tipo tradicional, de porte alto, muito utilizada em experimentos como simuladora do arroz vermelho (AgostinetTo, 2003; AgostinetTo et al. 2004). Esses genótipos foram usados para se ter variação considerável de ciclo, de muito precoce (IRGA 421) a tardio (EPAGRI 109) e representantes das duas subespécies de O. sativa.

Foram semeadas 30 sementes por balde, sendo realizada a quebra de dormência das sementes dos biótipos de arroz vermelho antes da semeadura, conforme MARCHEZAN (1994), deixando-se as sementes em estufa durante cinco dias a $42{ }^{\circ} \mathrm{C}$. Consideraramse o dia da emergência (EM) quando $50 \%$ das plântulas estavam visíveis acima do solo. No estádio V3 da escala de CounCE et al. (2000) realizou-se o desbaste, deixando-se 10 plântulas por balde, cinco das quais foram marcadas com arames coloridos, o que resultou em uma densidade de plantas de aproximadamente $200 \mathrm{pl} \mathrm{m}^{-2}$.

O manejo das plantas foi feito com base nas recomendações técnicas para a cultura do arroz irrigado (SosbaI, 2005) e a irrigação, realizada deixando-se uma lâmina de água de 5 a $7 \mathrm{~cm}$ nos baldes a partir do estádio V3 da escala de CouncE et al. (2000).

Diariamente, nas plantas marcadas, observouse a data de ocorrência dos seguintes estádios de desenvolvimento do arroz no colmo principal, segundo a escala de Counce et al. (2000): R2 (aparecimento do colar da folha bandeira), R3 (aparecimento da panícula ou panícula visível), R4 (antese, uma ou mais flores abertas na panícula), R8 (uma ou mais espiguetas com grãos com casca amarela) e R9 (maturação fisiológica: todas as espiguetas da panícula com grãos com casca marrom). 
Foram ainda identificados os estádios EB (emborrachamento, considerado quando havia um entumescimento no colmo principal, devido à presença da panícula, entre a última e penúltima folha do colmo principal) e R7 (uma ou mais espiguetas com grãos farináceos).

Dividiu-se o ciclo de desenvolvimento do arroz em duas fases: EM-R2 e R2-R9. Optou-se por esta divisão, pois a primeira fase (EM-R2) refere-se à fase de emissão de folhas enquanto a segunda fase (R2-R9) caracteriza-se pelo aparecimento das estruturas reprodutivas e pelo enchimento de grãos, todos os estádios facilmente identificáveis no campo e sem necessidade de destruir a planta.

Nas plantas marcadas mediram-se o comprimento (C) e a maior largura (L) - após expansão completa - da primeira, sexta, décima, décima segunda, décima quarta folhas e da folha bandeira, do colmo principal, contadas acropetalmente. A área $\left(\mathrm{AF}, \mathrm{cm}^{2}\right)$ final de cada uma dessas folhas foi calculada por (TIVET et al., 2001):

$$
\mathrm{AF}=\mathrm{C}^{*} \mathrm{~L}^{*} 0,74
$$

No colmo principal das plantas marcadas foi ainda medida a estatura final da planta (distância entre a superfície do solo e o ápice da panícula), o comprimento da panícula, o número final de folhas na antese e, semanalmente, o número de folhas e o comprimento da última e penúltima folha para o cálculo do estágio de HAUN (HS, folhas), que representa o número total de folhas na planta (NF) mais a razão entre o comprimento da última $\left(L_{n}\right)$ e o comprimento da penúltima folha $\left(\mathrm{L}_{\mathrm{n}-1}\right)$, utilizando-se a equação (HAUN, 1973):

$$
\mathrm{HS}=(\mathrm{NF}-1)+\mathrm{L}_{\mathrm{n}} / \mathrm{L}_{\mathrm{n}-1}
$$

Determinou-se, semanalmente, o número de perfilhos com atividade fotossintética evidente (verdes), nas plantas marcadas, até a ocorrência da antese no colmo principal.

A soma térmica diária ( $\mathrm{STd},{ }^{\circ} \mathrm{C}$ dia) foi calculada por (GILMORE e Rogers, 1958; ARNOLD, 1960; STRECK, 2002):

$$
\begin{aligned}
& \mathrm{STd}=(\mathrm{Tmed}-\mathrm{Tb}) .1 \text { dia } \\
& \text { quando } \mathrm{Tb} \leq \mathrm{Tmed} \leq \text { Tot } \mathrm{e} \\
& \mathrm{STd}=[(\mathrm{Tot}-\mathrm{Tb}) .(\text { Tmax-Tmed }) /(\text { Tmax-Tot })] .1 \text { dia }
\end{aligned}
$$

quando $T o t<T$ med $\leq$ Tmax , se Tmed $<\mathrm{Tb}$ então $\mathrm{Tmed}=\mathrm{Tb}$ e se Tmed $>$ Tmax então Tmed $=$ Tmax

em que: Tb, Tot, e Tmax são as temperaturas cardinais base, ótima e máxima para o desenvolvimento do arroz e Tmed é a temperatura média diária do ar calculada pela média aritmética entre a temperatura mínima e a temperatura máxima diária do ar. Assumiu-se $\mathrm{Tb}=$ $11^{\circ} \mathrm{C}$ (INFeld et al., 1998), Tot $=28^{\circ} \mathrm{C}$ (STeinMETZ, 2004) e Tmax $=40^{\circ} \mathrm{C}$ (GAO et al., 1992). As temperaturas mínima e máxima diária do ar foram medidas em uma estação meteorológica convencional, pertencente ao 8 . $^{\circ}$ Distrito de Meteorologia/Instituto Nacional de Meteorologia localizada a cerca de $200 \mathrm{~m}$ da área experimental.

A soma térmica acumulada $\left(\mathrm{STa},{ }^{\circ} \mathrm{C}\right.$ dia) a partir da emergência foi calculada por:

$$
\mathrm{STa}=\Sigma \mathrm{STd}
$$

O filocrono no colmo principal foi estimado para cada repetição (média de cinco plantas) como sendo o inverso do coeficiente angular da regressão linear entre HS e STa (KLEPPER et al., 1982; Wilhelm e MCMASTER, 1995; XUE et al., 2004).

Aos resultados aplicou-se análise de variância em esquema bifatorial, sendo as médias comparadas pelo teste Tukey a $5 \%$ de probabilidade. Quando a interação genótipo versus data de semeadura não foi significativa compararam-se as médias dos efeitos principais. Quando esta interação foi significativa comparam-se as médias das combinações genótipo versus datas de semeadura.

\section{RESULTADOS E DISCUSSÃO}

$\mathrm{Na}$ data de semeadura de 2/9/2004 não foi possível determinar os estágios da fase reprodutiva após R4 nos genótipos AVCPA, híbrido e BR-IRGA 409, pois na maioria das plantas desses genótipos houve senescência prematura, para a qual não se encontrou a causa provável. Na data de semeadura de 2/3/2005 nenhum dos genótipos atingiu R9 e a cultivar EPAGRI 109 sequer emitiu a folha bandeira, morrendo em razão das baixas temperaturas em maio de 2005.

A duração $\left({ }^{\circ} \mathrm{C}\right.$ dia) das fases e do ciclo total de desenvolvimento variou entre os genótipos e entre as datas de semeadura (Figura 1, Tabela 1). Independentemente do genótipo, a fase mais longa foi a fase EM-R2, perfazendo de 55 a $80 \%$ da duração do ciclo total dos genótipos. Quanto mais longo o ciclo total do genótipo, maior a percentagem da duração da fase EM-R2 em relação ao ciclo total. Para a cultivar IRGA 421 (muito precoce), a duração da fase EM-R2 foi em torno de $55 \%$, enquanto para a cultivar EPAGRI 109 (tardia), a fase EM-R2 representou em torno de $80 \%$ do ciclo total. A cultivar muito precoce IRGA 421 completou a fase EM-R2 entre 700 e $800^{\circ} \mathrm{C}$ dia. Já para as cultivares precoces e médias IRGA 416, IRGA 417, EEA 406 e IRGA 420 foram necessários de 1000 a 1200 ${ }^{\circ} \mathrm{C}$ dia. Para o híbrido foram necessários entre 1000 e $1100^{\circ} \mathrm{C}$ dia. E para as cultivares médias e tardias BR- 
IRGA 409, BRS 7 TAIM, EPAGRI 109 foram necessários de 1300 a $1700{ }^{\circ} \mathrm{C}$ dia. Para os biótipos de arroz vermelho AVCA e AVCPA foram necessários de 1200 a $1400{ }^{\circ} \mathrm{C}$ dia para completar esta fase. A fase R2-R9 variou bem menos entre as cultivares, ficando entre 500 e $600^{\circ} \mathrm{C}$ dia e sem relação com o ciclo da cultivar. As subfases entre R2 e R9 tiveram duração pequena, sendo R4-R7 a que teve duração maior (Figura 1).

Com base nos dados da Figura 1 e Tabela 1 observa-se que os biótipos de arroz vermelho geralmente possuem ciclo médio, sendo o biótipo AVCAA de ciclo mais longo que o biótipo AVCPA. O ciclo do biótipo AVCAA foi bastante longo quando semeado em $7 / 10 / 2004$, quase se igualando ao da cultivar tardia EPAGRI 109 na mesma data de semeadura. A implicação desses resultados é que em áreas com presença desses biótipos de arroz vermelho, o uso de cultivares de ciclo mais longo como a BR-IRGA 409 e EPAGRI 109, provavelmente, resultará em aumento do banco de sementes de arroz vermelho no solo, aspecto negativo no manejo desta planta daninha.

Verificou-se interação significativa genótipo versus data de semeadura para as variáveis área da sexta, décima, décima segunda e décima quarta folhas, estatura de planta, filocrono e número final de folhas (NFF) no colmo principal (Tabela 2). A análise estatística das variáveis foi desdobrada de acordo com a significância ou não da interação (Tabelas 3 e 4). O efeito dos fatores principais foi significativo para todas as variáveis, mesmo naquelas em que não houve interação significativa. Com exceção das variáveis área da folha bandeira e comprimento da panícula, nas demais, o quadrado médio do fator data de semeadura foi maior que o do fator genótipo (Tabela 2), indicando que o ambiente teve um maior efeito do que a constituição genética nestas variáveis.

A área da primeira folha foi maior nos dois biótipos de arroz vermelho e no híbrido e a área da folha bandeira foi maior nesses três genótipos e na cultivar EEA 406 (Tabela 3). Essa também foi a tendência para a área das folhas nas outras posições no colmo principal e nas diferentes datas de semeadura (Tabela 4). Datas de semeadura mais tardias tenderam a aumentar a área das folhas, independentemente da posição da folha no colmo principal (Tabelas 3 e 4). Esses resultados estão de acordo com a caracterização morfológica do arroz vermelho apresentada em diversos trabalhos que relatam folhas maiores no arroz vermelho do que nas variedades cultivadas de arroz (DiARRA et al., 1985; Kwon et al., 1992; Agostinetto, 2003). No entanto, Menezes et al. (2002) ao compararem sete biótipos de arroz vermelho com as cultivares IRGA 410 e IRGA 416 não observaram diferenças para área da folha bandeira, mas Noldin et al. (1999) notaram diferença para este parâmetro. A grande área foliar da cultivar EEA 406 deve-se ao fato de este genótipo ser do grupo tradicional e a semelhança de tamanho de folha com o arroz vermelho tem sido o motivo de sua utilização como planta simuladora dessa planta daninha em ensaios de competição (AgostinetTo, 2003). Já a grande área das folhas do híbrido é, provavelmente, o resultado do vigor híbrido (heterose) nesse genótipo.

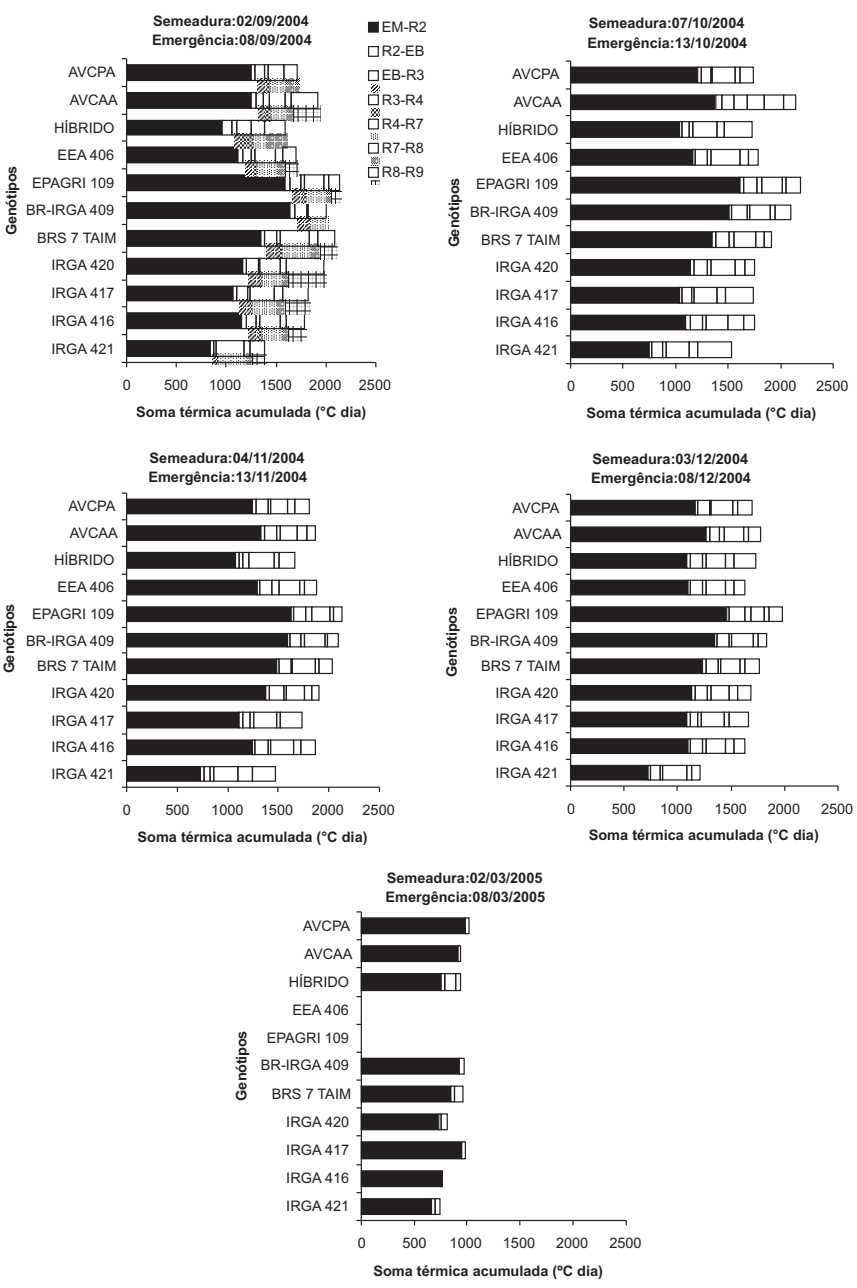

Figura 1. Soma térmica acumulada $\left({ }^{\circ} \mathrm{C}\right.$ dia) de fases do ciclo de desenvolvimento de dois biótipos de arroz vermelho e de nove genótipos de arroz irrigado em cinco datas de semeadura durante o ano agrícola 2004/2005. $\mathrm{EM}=$ emergência; $\mathrm{R} 2$ =aparecimento do colar da folha bandeira; $\mathrm{EB}=$ emborrachamento; $\mathrm{R} 3=$ aparecimento da panícula; $\mathrm{R} 4=$ antese; $\mathrm{R} 7=\mathrm{um}$ ou mais grãos farináceos; $\mathrm{R} 8=$ um ou mais grãos amarelos; $\mathrm{R} 9=$ todas as espiguetas da panícula com grãos com casca marron (maturação fisiológica); AVCPA = arroz vermelho casca preta aristado; AVCAA = arroz vermelho casca amarela aristado. Santa Maria (RS), 2004/2005. 
Tabela 1. Duração $\left({ }^{\circ} \mathrm{C}\right.$ dia) das fases emergência ao aparecimento do colar da folha bandeira (EM-R2), aparecimento do colar da folha bandeira à maturação fisiológica (R2-R9) e ciclo total (EM-R9) de dois biótipos de arroz vermelho e de nove genótipos de arroz cultivado. Santa Maria (RS), 2004/2005

\begin{tabular}{lcrr}
\hline Genótipos & EM-R2 & R2-R9 & EM-R9 \\
\hline AVCPA $\left({ }^{1}\right)$ & $1217,6( \pm 18,4)^{*}$ & $543,1( \pm 10,8)$ & $1748,6( \pm 29,2)$ \\
AVCAA $\left(^{2}\right)$ & $1308,0( \pm 27,0)$ & $617,0( \pm 59,5)$ & $1925,0( \pm 78,8)$ \\
HÍBRIDO & $1036,8( \pm 27,7)$ & $637,6( \pm 21,9)$ & $1674,4( \pm 33,6)$ \\
EEA 406 & $1170,0( \pm 41,8)$ & $577,3( \pm 19,5)$ & $1747,3( \pm 54,1)$ \\
EPAGRI 109 & $1573,2( \pm 37,6)$ & $536,0( \pm 15,6)$ & $2109,2( \pm 45,3)$ \\
BR-IRGA 409 & $1522,7( \pm 62,5)$ & $520,7( \pm 27,8)$ & $2006,4( \pm 77,5)$ \\
BRS 7 TAIM & $1353,7( \pm 49,1)$ & $589,9( \pm 45,8)$ & $1957,4( \pm 70,3)$ \\
IRGA 420 & $1202,3( \pm 58,9)$ & $625,7( \pm 64,1)$ & $1828,0( \pm 66,1)$ \\
IRGA 417 & $1074,6( \pm 16,4)$ & $663,5( \pm 38,5)$ & $1738,1( \pm 31,9)$ \\
IRGA 416 & $1147,3( \pm 31,6)$ & $608,9( \pm 28,0)$ & $1756,3( \pm 49,4)$ \\
IRGA 421 & $761,9( \pm 27,6)$ & $638,6( \pm 72,2)$ & $1400,5( \pm 70,8)$ \\
\hline
\end{tabular}

* Média de quatro datas de semeadura. Os valores entre parênteses representam o erro-padrão da média. $\left({ }^{1}\right)$ Arroz vermelho casca preta aristado. $\left({ }^{2}\right)$ Arroz vermelho casca amarela aristado.

Tabela 2. Resumo da análise de variância com os valores dos quadrados médios para diferentes parâmetros de crescimento e desenvolvimento de dois biótipos de arroz vermelho e de nove genótipos de arroz cultivado. Santa Maria (RS), 2004/2005

\begin{tabular}{|c|c|c|c|c|c|}
\hline \multirow{2}{*}{ Fonte de variação } & \multicolumn{5}{|c|}{ Quadrado médio } \\
\hline & AF1 & AF6 & AF10 & AF12 & AF14 \\
\hline Genótipo (G) & $1,37^{* *}$ & $82,61^{* *}$ & $538,12^{* *}$ & $487,37^{* *}$ & $589,79 * *$ \\
\hline Data de semeadura (S) & $1,86^{* *}$ & $550,57^{* *}$ & $639,67^{* *}$ & $4104,55^{* *}$ & $653,45^{* *}$ \\
\hline$G \times S$ & 0,052 & $21,03^{* *}$ & $90,86^{* *}$ & $46,09 * *$ & $60,61^{* *}$ \\
\hline \multirow{2}{*}{ Fonte de variação } & \multicolumn{5}{|c|}{ Quadrado médio } \\
\hline & AFB & EP & $\mathrm{F}$ & $\mathrm{CP}$ & NFF \\
\hline Genótipo (G) & $313,96^{* *}$ & $1034,96^{* *}$ & $1183,24^{* *}$ & $20,05^{* *}$ & $41,27^{* *}$ \\
\hline Data de semeadura (S) & $268,94^{* *}$ & $1550,53^{* *}$ & $3484,22^{* *}$ & $18,46^{* *}$ & $262,93^{* *}$ \\
\hline$G \times S$ & 33,26 & $134,02^{* *}$ & $68,33^{* *}$ & 2,94 & $15,90^{* *}$ \\
\hline
\end{tabular}

** Significativo a 1\%; AF1 = área da primeira folha; AF6 = área da sexta folha; AF10 = área da décima folha; AF12 = área da décima segunda folha; AF14 = área da décima quarta folha. AFB = área da folha bandeira; $\mathrm{EP}=$ estatura de planta; $\mathrm{F}=$ filocrono; $\mathrm{CP}=\mathrm{comprimento}$ de panícula; NFF = número final de folhas.

A maior estatura de planta foi observada para a cultivar EEA 406 e para os dois biótipos de arroz vermelho em todas as datas de semeadura (Tabela 5). A maior estatura da cultivar EEA 406 deve-se ao fato de ser uma cultivar antiga, de porte elevado, característica de genótipos de arroz que antecederam as cultivares modernas usadas atualmente no Rio Grande do Sul e Santa Catarina, de porte baixo. Com relação à estatura de biótipos de arroz vermelho, Menezes et al. (2002) observaram estatura aos 20, 50 e 80 DAE e constataram diferenças entre biótipos de arroz vermelho e as cultivares de arroz. KwON et al. (1992) relataram que aos 60 DAE plantas de arroz vermelho estavam com estatura $46 \%$ e $55 \%$ superiores à das cultivares Newbonnet e Lemont. Do mesmo modo NoLDIN et al. (1999) verificaram estaturas $31 \%$ e $26 \%$ superiores em plantas de biótipos de arroz vermelho, comparativamente às cultivares-padrão. A maior estatura das plantas de arroz vermelho confere a esta planta daninha grande capacidade de competição pelo recurso radiação solar. Além disso, maior estatura confere maior sucetibilidade ao acamamento, um aspecto prejudicial a mais em lavouras de arroz, pois pode também ocorrer acamamento do arroz cultivado. 
Tabela 3. Área da primeira folha (AF1), área da folha bandeira (AFB) e comprimento da panícula (CP) no colmo principal de dois biótipos de arroz vermelho e de nove genótipos de arroz cultivado quando não houve interação entre genótipo e data de semeadura. Santa Maria, RS, 2004/2005

\begin{tabular}{lccc}
\hline Genótipo & AF1 cm $\mathrm{cm}^{2}$ & AFB & CP \\
\cline { 2 - 4 } AVCPA $^{1}$ & $1,78 \mathrm{~A}$ & $31,1 \mathrm{~A}$ & $20,4 \mathrm{AB}$ \\
AVCAA $^{2}$ & $1,45 \mathrm{~B}$ & $29,4 \mathrm{~A}$ & $21,0 \mathrm{~A}$ \\
HÍBRIDO & $1,45 \mathrm{~B}$ & $30,4 \mathrm{~A}$ & $18,9 \mathrm{BCD}$ \\
EEA 406 & $1,04 \mathrm{CD}$ & $29,4 \mathrm{~A}$ & $20,3 \mathrm{AB}$ \\
EPAGRI 109 & $1,11 \mathrm{C}$ & $19,9 \mathrm{C}$ & $18,8 \mathrm{BCDE}$ \\
BR-IRGA 409 & $0,73 \mathrm{E}$ & $21,2 \mathrm{BC}$ & $18,2 \mathrm{CDE}$ \\
BRS TAIM & $0,95 \mathrm{CDE}$ & $23,6 \mathrm{BC}$ & $18,9 \mathrm{BCDE}$ \\
IRGA 420 & $0,80 \mathrm{DE}$ & $20,0 \mathrm{C}$ & $16,9 \mathrm{E}$ \\
IRGA 417 & $0,77 \mathrm{DE}$ & $20,6 \mathrm{C}$ & $19,6 \mathrm{ABC}$ \\
IRGA 416 & $1,01 \mathrm{CDE}$ & $23,7 \mathrm{BC}$ & $18,9 \mathrm{BCD}$ \\
IRGA 421 & $0,84 \mathrm{CDE}$ & $26,8 \mathrm{AB}$ & $17,1 \mathrm{DE}$ \\
\hline Datas de semeadura & AF1 & AFB & $\mathrm{CP}$ \\
\hline & & & $\mathrm{cm}$ \\
$2 / 9 / 2004$ & - & $24,3 \mathrm{~B}$ & $19,7 \mathrm{~A}$ \\
$7 / 10 / 2004$ & - & $22,9 \mathrm{~B}$ & - \\
$4 / 11 / 2004$ & $0,85 \mathrm{~B}$ & $28,6 \mathrm{~A}$ & $18,9 \mathrm{~B}$ \\
$3 / 12 / 2004$ & $1,22 \mathrm{~A}$ & - & $18,4 \mathrm{~B}$ \\
$2 / 03 / 2005$ & $1,19 \mathrm{~A}$ & $24,7 \mathrm{~B}$ & - \\
\hline
\end{tabular}

Médias seguidas por mesma letra na vertical não diferem entre si pelo Teste Tukey a $5 \%$ de probabilidade.

${ }^{(1)}$ Arroz vermelho casca preta aristado; $\left({ }^{2}\right)$ Arroz vermelho casca amarela aristado; - Dados não medidos na época.

Com relação ao parâmetro de crescimento comprimento da panícula, nos dois biótipos de arroz vermelho e a cultivar EEA 406, constataram estatisticamente maior comprimento (Tabela 3). Similarmente, o parâmetro de desenvolvimento filocrono também foi maior nos dois biótipos de arroz vermelho e na cultivar EEA 406 (Tabela 5). Não foram verificados na literatura relatos de diferença de velocidade de emissão de folhas entre o arroz vermelho e o arroz cultivado. O menor filocrono (maior velocidade de emissão de folhas) dos genótipos modernos de arroz revela que esses genótipos têm, nesse parâmetro, maior capacidade competitiva, que os biótipos de arroz vermelho. Esta é, portanto, uma característica a ser mantida e estimulada em programas de melhoramento para novas cultivares de arroz. A cultivar EEA 406 destacou-se em todas as datas de semeadura com o maior filocrono, ou seja, tem uma velocidade de emissão de folhas baixa, certamente uma característica comum a cultivares antigas de arroz.

O número final de folhas (NFF) variou com o genótipo, sendo maior no AVCPA, EEA 406 e EPAGRI 109 e menor no IRGA 421 (Tabela 5). Entre datas de semeadura em geral, o NFF diminuiu com o atraso da semeadura. O NFF no colmo principal tem relação direta com duração do ciclo de desenvolvimento dos genótipos, onde quanto maior for o NFF, maior o ciclo de desenvolvimento (STRECK et al., 2006).

Para o número de perfilhos planta ${ }^{-1}$ na primeira data de semeadura $(2 / 9 / 2004)$, o biótipo de arroz vermelho AVCAA foi o de maior número de perfilhos e o biótipo AVCPA, o menor número de perfilhos (Figura 2). Para as outras datas de semeadura a diferença entre genótipos foi menor ou inexistente. Destaca-se, ainda, o AVCPA com menor número de perfilhos na semeadura de 04/11/2004. As diferenças de capacidade de perfilhamento de biótipos de arroz vermelho obtidos neste estudo se unem a resultados previamente relatados por outros autores (KwON et al., 1992; Noldin et al., 1999; MENEZES et al., 2002) para reforçar a grande variabilidade nessa característica entre os biótipos de arroz vermelho.

Analisando-se de forma conjunta os resultados, é possível perceber que os biótipos de arroz vermelho AVCPA e AVCAA possuem características de crescimento e desenvolvimento intermediárias entre as cultivares (e híbrido) de ciclo muito precoce e precoce (IRGA 421, híbrido, IRGA 417, IRGA 416, EEA 406 e IRGA 420) e as cultivares de ciclo médio, médio-tardio e tardio (BRS 7 TAIM, BR-IRGA 409 e EPAGRI 109). Constata-se também haver variação dessas características entre os biótipos AVCPA e AVCAA. 


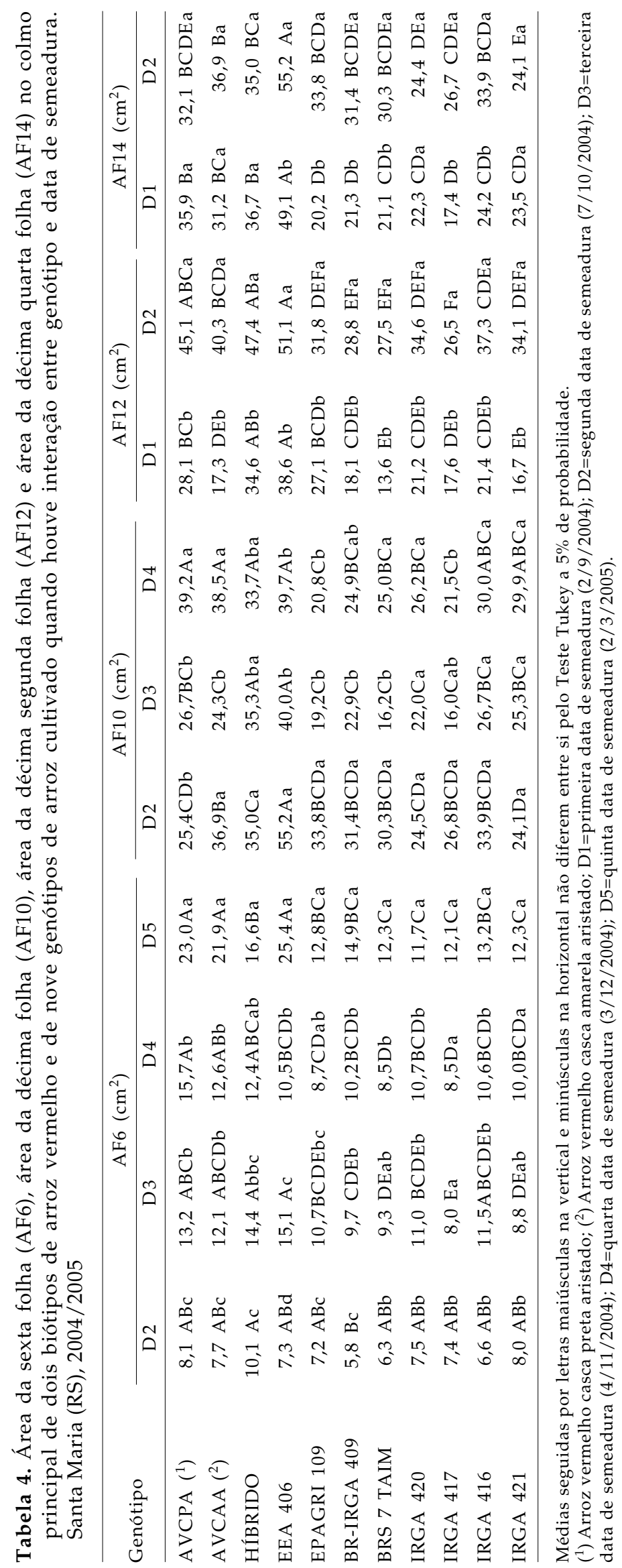




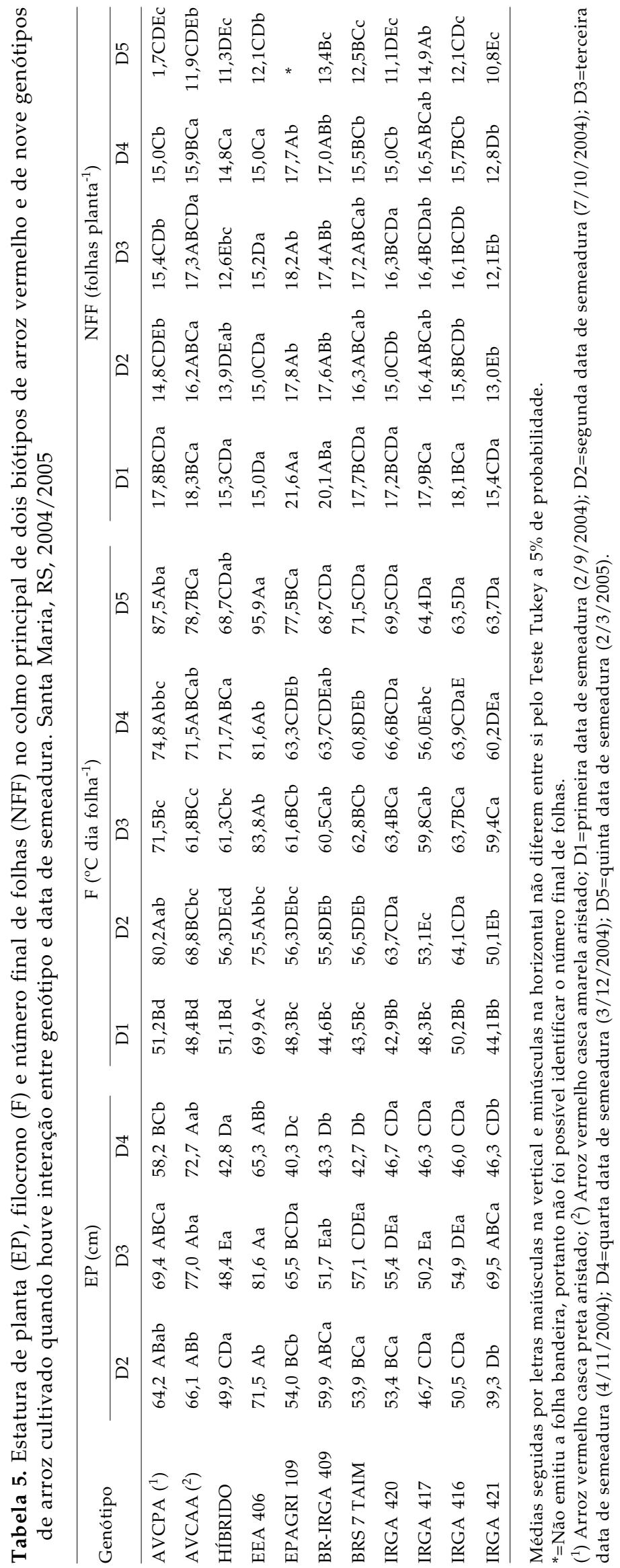



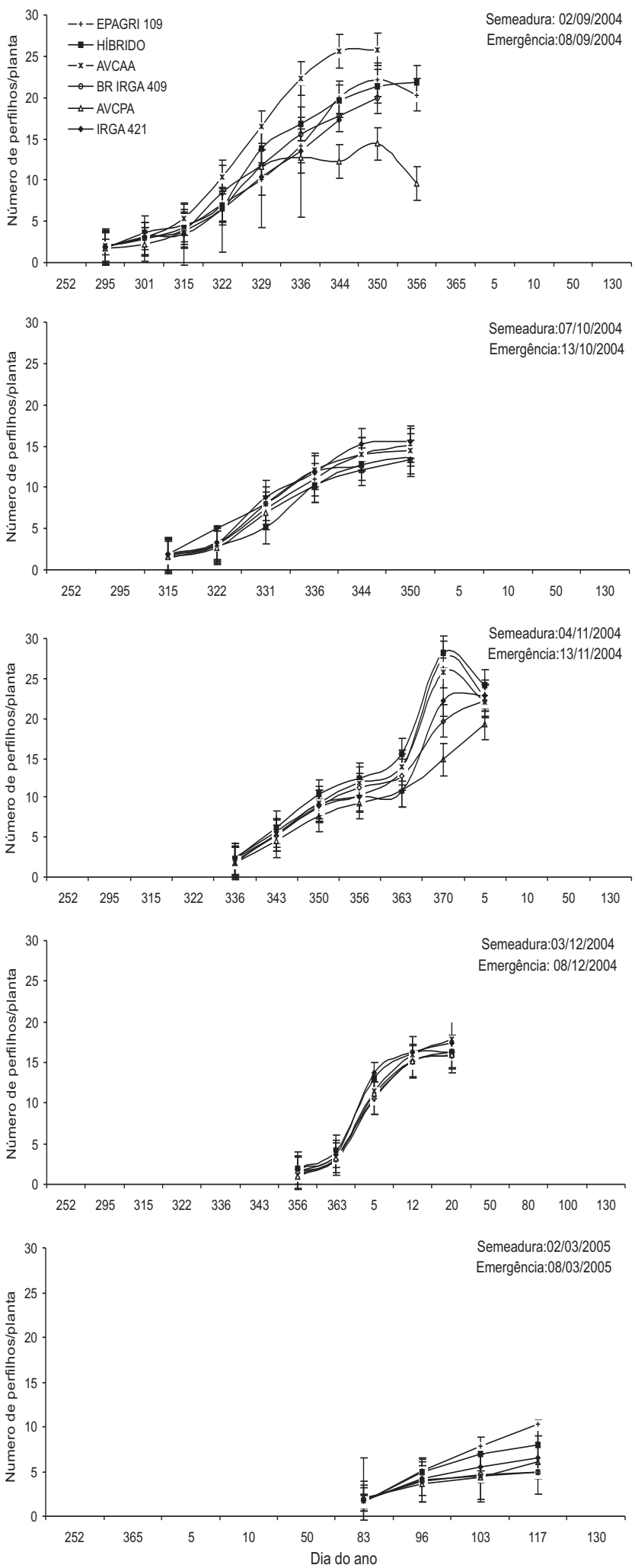

Figura 2. Número de perfilhos planta ${ }^{-1}$ de dois biótipos de arroz vermelho e de genótipos de arroz cultivado em cinco datas de semeadura durante o ano agrícola $2004 / 2005$. AVCPA $=$ arroz vermelho casca preta aristado; AVCAA = arroz vermelho casca amarela aristado. Santa Maria (RS), 2004/2005.
Esse comportamento reflete a natureza dos biótipos de arroz vermelho que, pelo fluxo gênico, sofrem introgressão de características das cultivares. Ainda, por estarem sujeitos ao processo de seleção natural, fixam as características relacionadas à habilidade competitiva, como velocidade de crescimento inicial, área foliar e perfilhamento maiores (DiARra et al., 1985; GeAly et al., 2003).

Portanto, esta posição intermediária das características de crescimento e desenvolvimento dos biótipos de arroz vermelho, entre cultivares modernas de porte baixo e ciclo curto, predominantemente cultivadas hoje, e cultivares tradicionais, de porte mais elevado e ciclo longo, reflete a condição de planta daninha em constante processo de evolução e associação com a cultura que infesta.

\section{CONCLUSÕES}

1. Os biótipos de arroz vermelho, em geral, possuem ciclo médio em relação aos genótipos cultivados, sendo o biótipo AVCAA de ciclo mais longo que o biótipo AVCPA, mas em épocas de semeadura cedo (outubro), o biótipo AVCAA tem ciclo longo comparado com os genótipos cultivados.

2. Os biótipos de arroz vermelho possuem folhas, estatura, panícula e filocrono maiores que os genótipos modernos de arroz cultivado.

3. O número final de folhas no colmo principal dos biótipos de arroz vermelho é menor que as cultivares de ciclo médio e tardio e maior que as cultivares de ciclo precoce e muito precoce.

4. Os biótipos de arroz vermelho têm capacidade de perfilhamento variável e dependente da época de semeadura.

5. As variáveis crescimento e desenvolvimento dos biótipos de arroz vermelho conferem a essa espécie daninha alta capacidade de competição com o arroz cultivado e o melhoramento genético deve considerar essas variáveis, em especial o filocrono e o número final de folhas na haste principal, no portfolio de características desejáveis durante a avaliação e seleção de linhagens avançadas de arroz.

\section{AGRADECIMENTOS}

Aos alunos de graduação do curso de Agronomia da Universidade Federal de Santa Maria, Hamilton Telles Rosa, Lidiane Cristine Walter e Cátia Camera pela ajuda na coleta e no processamento dos dados. 


\section{REFERÊNCIAS}

AGOSTINETTO, D. Aplicação de modelos matemáticos para estimar interferência de genótipos de arroz concorrentes e níveis de dano econômico em arroz irrigado. Porto Alegre: UFRGS, 2003, 200p. Tese (Doutorado - Plantas de lavoura) Programa de Pós-graduação em Fitotecnia, Universidade Federal do Rio Grande do Sul, 2003.

AGOSTINETTO, D.; FLECK, N.G.; RIZZARDI, M.A.; BIANCHI, M.A.; SILVA, P.R.F.de. Comparação de modelos matemáticos na estimativa das perdas de produtividade de grãos em arroz irrigado.Pesquisa Agropecuária Brasileira, Brasília, v.39, n.9, p.847-856, 2004.

ARNOLD, C.Y. Maximum-minimum temperatures as a basis for computing heat units. Journal of the American Society for Horticultural Sciences, Boston, v. 76, p. 682-692, 1960.

AZAMBUJA, I.H.V.; VERNETTI Jr., MAGALHÃES Jr., A.M. Aspectos socioeconômicos da produção do arroz. In: GOMES, A.S.; MAGALHÃES Jr., A.M. Arroz irrigado no Sul do Brasil. 1ed. Brasília: Embrapa, 2004. p. 23-44.

COUNCE, P.; KEISLING, T.C.; MITCHELL, A.J. A uniform, objective, and adaptive system for expressing rice development. Crop Science, Madison, v.40, n.2, p. 436-443, 2000.

DIARRA, A.; SMITH Jr., R.J.; TALBERT, R.E. Growth and morphological characteristics of rice (Oryza sativa) biotypes. Weed Science, v.33, p.310-314, 1985

EMBRAPA. Sistema Brasileiro de Classificação de Solos. Brasília: Embrapa produções de informações, 1999. 412 p.

FAGERIA, N.K.; STONE, L.F.; SANTOS, A.B. dos. Manejo da fertilidade do solo para o arroz irrigado. 1ed. Santo Antonio de Goiás: Embrapa Arroz e Feijão, 2003. 250 p.

GAO, L.; JUN, Z.; HUANG, Y.; ZHANG, L. Rice clock model a computer model to simulate rice development. Agricultural and Forest Meteorology, Amsterdam, v.60, n.1, p.1 - 16, 1992.

GEALY, D.R.; MITTEN, D.H.; RUTGER, J.N. Gene flow between red rice (Oryza sativa) and herbicide-resistant (O. sativa): implications for weed management. Weed Technology, v.17, p.627-645, 2003.

GILMORE, E.C.JR.; ROGERS, J. S. Heat units as a method of measuring maturity in corn. Agronomy Journal, Madison, v.50, n.10, p.611-615, 1958.

HAUN, J.R. Visual quantification of wheat development. Agronomy Journal, Madison, v.65, p.116-119, 1973.

INFELD, J. A.; SILVA, J. B.; ASSIS, F. N. Temperatura base e graus-dia durante o período vegetativo de três grupos de cultivares de arroz irrigado. Revista Brasileira de Agrometeorologia, Santa Maria, v.6, n.2, p.187-191, 1998.

IRGA. Dados de safra. Série histórica da área plantada, produção e rendimento. Disponível na internet. http:/ / www.irga.rs.gov.br/ dados.htm. Online. Acesso em agosto de 2006.
KLEPPER, B.; RICKMAN, R.W.; PETERSON, C.M. Quantitative characterization of vegetative development in small cereal grains. Agronomy Journal, Madison, v.7, p.780-792, 1982.

KWON, S.L.; SMITH, R.J.Jr.; TALBERT, R.E. Competitive growth and development of red rice (Oryza sativa) eand rice (Oryza sativa). Weed Science, v.40, n.1, p.57-62, 1992.

LOPES, M.C.B.; LOPES, S.I.G.; CARMONA, P.S.;SANTOS, A.S.; LIMA, A.L.; COSTA, M.S. Avaliação de genótipos, no ensaio de rendimento preliminar, do programa de melhoramento genético do instituto Rio Grandense do Arroz, na safra 20003/ 2004. In: CONGRESSO BRASILEIRO DE ARROZ IRRIGADO, IV, Santa Maria, 2005. Anais... Santa Maria: Orium, v.1, p.4446, 2005a.

LOPES, M.C.B.; LOPES, S.I.G.; SOARES, A., FREITAS, J.P.M.; CREMONESI, J.; CORDERO, E.J. NEVES, G.; JAEGER, R.L. LIMA, A.L; COSTA, M.S.;WANG, L.; MARCHEZAN, E.; GARCIA,G.A.; TOMAZZI, D. Avaliação de genótipos de arroz híbrido do programa de melhoramento genético do Instituto Rio Grandense do Arroz, na safra 2003/2004. In: CONGRESSO BRASILEIRO DE ARROZ IRRIGADO, 4., 2005, Santa Maria. Anais...Santa Maria: Orium, v.1,p.38-40, 2005b.

LOPES, S.I.G.; LOPES, M.C.B.; LIMA, A.L.; SANTOS, A.S.; FREITAS, P.R.; COSTA, M.S.; LEAL, C.E.B. Avaliação de linhagens do viveiro. "FLAR TROPICAL-2002" em cachoeirinha e Uruguaiana, safra 2003/2004. In: CONGRESSO BRASILEIRO DE ARROZ IRRIGADO, 4., 2005, Santa Maria. Anais...Santa Maria: Orium, v.1, p.50-51, 2005c.

LOPES, S.I.G.; LOPES, M.C.B.; LIMA, A.L.; SANTOS, A.S.; FREITAS, P.R.; CREMONESI, J.; COSTA, M.S.; LEAL, C.E.B. Avaliação do ganho genético do programa de melhoramento do IRGA no período de 1961 a 2004. In: CONGRESSO BRASILEIRO DE AGROMETEOROLOGIA, 4., 2005, Santa Maria. Anais... Santa Maria: Orium, v.1, p.67-69, 2005d.

MARCHEZAN, E. Sistemas de cultivo e rotação de cultura no controle do arroz vermelho em várzeas. Santa Maria, 1993, 65 p. Tese (Acesso a classe de professor titular) - Universidade Federal de Santa Maria, 1993.

MARCHEZAN, E. Arroz vermelho: Caracterização, prejuízos e controle. Ciência Rural, Santa Maria, v.24, n.2, p.415-421, 1994.

MARCHEZAN, E.; ÁVILA, L.A.; MAGALHÃES Jr., A.M.; MACHADO, S.L.; PETRINI, J.A. Controle do arroz vermelho. In: GOMES, A.S.; MAGALHÃES JUNIOR, A.M. Arroz irrigado no Sul do Brasil. 1.ed. Brasília: Embrapa, 2004. p. 547-573.

MARIOT, C.H.P.; SILVA, P.R.F.; MENEZES,V.G.; TEICHMANN, L.L. Resposta de duas cultivares de arroz irrigado a densidade de semeadura e a adubação nitrogenada. Pesquisa Agropecuária Brasileira, Brasília, v.38, n.2, p. 233241, 2003.

MENEZES, V. G.; SILVA, P.R.F.; CARMONA, R.; REZERA, F.; MARIOT, C..H. Interferência do arroz vermelho no rendimento de engenho de cultivares de arroz irrigado. Ciência Rural, Santa Maria, v.27, n.1, p.27-30, 1997. 
MENEZES, V.G.; AGOSTINETTO, D.; FLECK, N.G.; SILVEIRA, C.A. Caracterização de biótipos de arroz vermelho em lavouras de arroz no Estado do Rio Grande do Sul. Planta Daninha, v.20, n.2, p.221-227, 2002.

MORENO, J. A. Clima do Rio Grande do Sul. Porto Alegre: Secretaria da Agricultura, 1961. 46p.

NOLDIN, J.A.; CHANDLER, J.M.; McCAULEY, G.N. Red rice (Oryza sativa) biology. I. Characterization of red rice ecotypes. Weed Technology, v.13, n.1, p.12-18, 1999.

RICKMAN, R.W.; KLEPPER, B.L. The phyllochron: Where do we go in the future? Crop Science, Madison, v.35, n.1, p.44-49, 1995.

SKINNER, R.H.; NELSON, C.J. Elongation of the grass leaf its relationship to the phyllochron. Crop Science, Madison, v.35, n.1, p.4-10, 1995.

SOSBAI (Sociedade Sul Brasileira de Arroz irrigado). Arroz irrigado: Recomendações técnicas da pesquisa para o sul do Brasil. Santa Maria: SOSBAI, 2005. 159p.

STEINMETZ, S. Influência do clima na cultura do arroz irrigado no Rio Grande do Sul. In: GOMES, A.S.; MAGALHÃES Jr., A.M. Arroz irrigado no Sul do Brasil. Brasília: Embrapa, 2004. p. $45-74$.
STRECK, N.A. A generalized nonlinear air temperature response function for node appearance rate in muskmelon (Cucumis melo L.). Revista Brasileira de Agrometeorologia, Santa Maria, v.10, n.1, p.105-111, 2002.

STRECK, N.A.; BOSCO, L.C.; MICHELON, S.; WALTER, L.C.; MARCOLIN, E. Duração do ciclo de desenvolvimento de cultivares de arroz em função da emissão de folhas no colmo principal. Ciência Rural, Santa Maria, v.36, n.4, p.1086-1093, 2006.

TIVET, F.; PINHEIRO, B.S.da.; RAISSAC, M.de.; DINGKUHN, M. Leaf blade dimensions of rice (Oryza sativa L. and Oryza sativa glaberrima Steud.) relationships between tillers and the main stem. Annals of Botany,London, v.88, p.507-511, 2001.

WILHELM, W.W.; McMASTER, G.S. Importance of the phyllochron in studying development and growth in grasses. Crop Science, Madison, v.35, n.1, p.1-3, 1995.

XUE, Q.; WEISS, A.; BAENZIGER, P.S. Predicting leaf appearance in field grown winter wheat: evaluating linear and non-linear models. Ecological Modelling, Amsterdan, v.175, p.261-270, 2004. 